\title{
ORQUIECTOMIA DIREITA: CONSEQUÊNCIA DE DIAGNÓSTICO TARDIO DE TORÇÃO TESTICULAR
}

\section{RIGHT ORCHIECTOMY: CONSEQUENCE REGARDING LATE DIAGNOSIS OF TESTICULAR TORSION}

Ilana Carolina Sartori ${ }^{1}$, Isabela Hayashi ${ }^{1}$, Jessiane Karen Silvestre ${ }^{1 *}$, José Juares Neto ${ }^{1}$, Julia Corso Marafon ${ }^{1}$, Ângelo Yassushi Hayashi ${ }^{2}$.

1UNINGÁ - Centro Universitário Ingá, Maringá, PR, Brasil.

${ }^{2}$ Hospital Norte Paranaense, Arapongas, PR, Brasil.

*jessianesilvestre@hotmail.com

\section{RESUMO}

A torção testicular é caracterizada pela interrupção do suprimento sanguíneo proveniente da rotação do cordão espermático e possui como etiologias o trauma local, atividades físicas que aumentem o reflexo cremastérico, congestão vascular nos indivíduos com epididimite, inflamação testicular. Seu pico de incidência é na infância e adolescência. A interrupção do fluxo sanguíneo justifica a urgência do diagnóstico e tratamento, já que sua demora pode levar a necrose e perda do mesmo. Dessa forma, pacientes com uma evolução de 4 a 8 horas apresentam melhor prognóstico que aqueles com uma evolução de 12 horas ou mais, sendo esses os que apresentam maiores indicações de orquidectomia. Além disso, após a distorção ou retirada do testículo acometido, o testículo contralateral é avaliado e a orquidopexia poderá ser indicada, com a finalidade de diminuir a probabilidade de uma futura torção desse testículo. Este estudo teve como objetivo a descrição de um relato de caso sobre torção testicular direito com 3 dias de evolução e, qual diagnóstico, tratamento cirúrgico escolhido. Para o relato de caso foram utilizados dados da equipe medica que assistiu o paciente, dados do prontuário do paciente e exame de imagem diagnósticos. Paciente A. S. F., masculino, 13 anos, com história de febre, êmese e dor testicular direita abrupta, espontânea, evoluiu com edema e hiperemia há 3 dias, com leve alivio ao uso de analgesia oral. Ao exame físico paciente encontrava-se com hemibolsaescrotal direita dolorosa a palpação, edemaciada, eritematosa, endurecida, com ausência do reflexo cremastérico e sinal de Prehn positivo. Ultrassonografia + Doppler de bolsa escrotal apresentou testículo direito com dimensões aumentadas e ecotextura heterogênea, mais hipoecogênico em relação ao contralateral, sem fluxo ao Doppler. Testículo direito medindo 3,0 $\mathrm{x}$ $3,8 \times 2,4 \mathrm{~cm}$ e apresentando volume de $14,4 \mathrm{~cm}^{3}$. Foi realizado exploração cirúrgica escrotal com identificação de torção testicular a direita em processo de isquemia. Realizou-se orquiectomia direita, orquidopexia esquerda e ligadura do cordão esquemático esquerdo com Vicril 1,0. Paciente pós-cirurgico afebril, sem queixas álgicas, diurese positiva, sem sinais flogísticos e indicado alta hospitalar. Tendo em vista o paradigma do caso, a procura médica precoce, precisão diagnóstica e a intervenção no momento adequado fazem diferença no prognóstico do paciente. Isto faz ser fundamental, antes de qualquer outro aspecto, a educação do médico não especialista e mesmo dos jovens e famílias 
quanto à necessidade de procurar socorro rapidamente em caso de dor escrotal aguda.

Palavras-chave: Criança e adolescente. Diagnóstico tardio. Orquiectomia. Torção testicular. Urgência. 